\title{
Genetic regulation of flower development
}

\author{
USHA VIJAYRAGHAVAN* \\ Department of Microbiology and Cell Biology, Indian Institute of Science, Bangalore 560012 , \\ India
}

MS received 7 September 1995; revised 25 January 1996

\begin{abstract}
Flower development provides a model system to study mechanisms that govern pattern formation in plants. Most flowers consist of four organ types that are present in a specific order from the periphery to the centre of the flower. Reviewed here are studies on flower development in two model species: Arabidopsis thaliana and Antirrhinum majus that focus on the molecular genetic analysis of homeotic mutations affecting pattern formation in the flower. Based on these studies a model was proposed that explains how three classes of regulatory genes can together control the development of the correct pattern of organs in the flower. The universality of the basic tenets of the model is apparent from the analysis of the homologues of the Arabidopsis genes from other plant species.
\end{abstract}

Keywords. Flower development; homeotic mutations; Arabidopsis thaliana.

\section{Introduction}

All of the structures of the adult flowering plant are derived from the activity of two groups of dividing cells: the shoot apical meristem and the root meristem. These meristematic cells are laid down in the developing embryo and they form the source for all the subsequent new plant structures. Thus, unlike what is seen in animal morphogenesis, plants retain throughout their lives groups of dividing undifferentiated cells, and therefore never stop developing. Arabidopsis thaliana, a member of the mustard family, is now a popular model system for molecular genetic analysis of plant development. In this plant, the shoot apical meristem puts out, in the early stages of the life cycle, groups of cells that form primordia for the vegetative structures of the plant (either leaves or branches). The plant then switches from a vegetative developmental programme to one that is capable of forming the reproductive structures, the flowers (figure la). This switch in development depends on the presence of appropriate cues that are both genetic and environmental. After floral induction the apical meristem produces groups of cells whose fate is specified as that of a floral meristem. The floral meristem is determinate in its development unlike the shoot apical meristem which is indeterminate. Each floral meristem develops into a single flower by specifying the development of concentric rings of floral organs in the order sepals, petals, stamens and carpels from the periphery to the centre of the flower (figure $\mathrm{lb}$ and figure 2a). Molecular genetic analysis of the specification of the floral meristem and the ordered development of the floral organs on this meristem has benefited from studies in two distantly related flowering plants; Arabidopsis thaliana and Antirrhinum majus. In both these species working models of flower

*Fax, 091-80-3341683; Email, uvr@mcbl.iisc.ernet.in. 


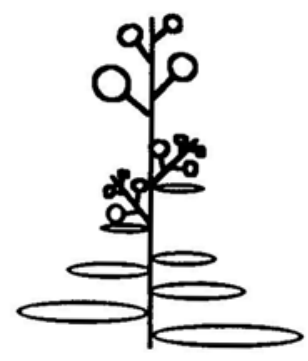

Inflorescence Apical Meristem

Vegetative Apical Meristem

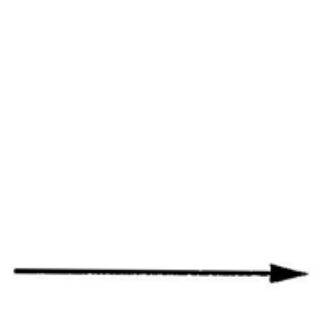

(1)

B

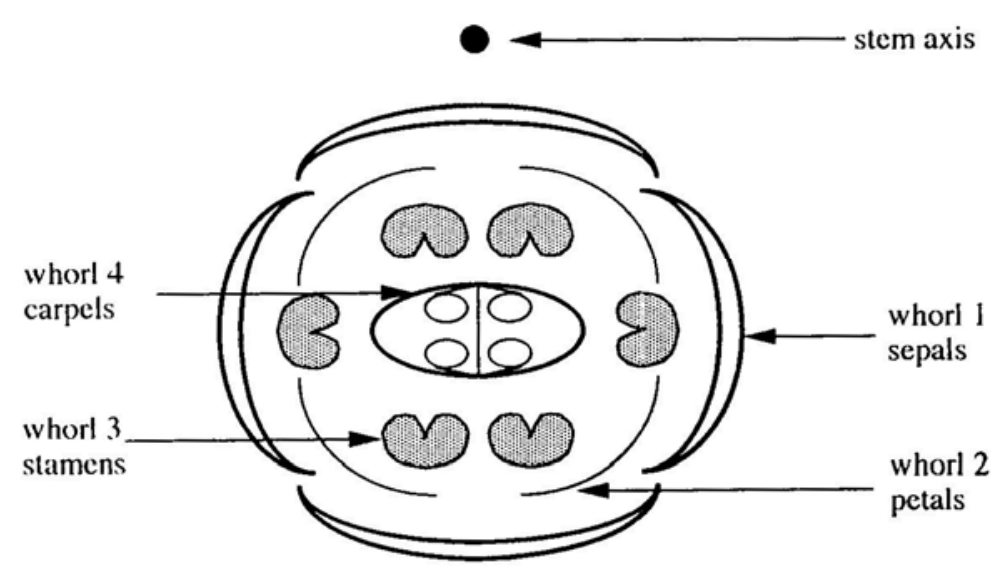

\section{WILD TYPE}

Figure 1. (A) Schematic representation on the left of an Arabidopsis plant in the vegetative phase of development where rosette leaves are produced. On the right is a representation of a plant that is florally induced. Here after the production of a few of cauline leaves the primary inflorescence meristem produces individual floral primordia. The axils of the cauline leaves bear secondary inflorescence meristems. (B) Floral diagram of an Arabidopsis flower. Typical of the Crucifer family to which it belongs this flower bears four sepals in the outermost whorl, internal to which are four petals, internal to them are two lateral and four medial stamens. Internal to these stamens is the central two carpel gynoecium.

development are derived from the genetic analysis of homeotic mutations. The term "homeotic" refers to mutations where the development of a normal organ takes place at a position normally occupied by a different organ (Bateson 1894). Genetic analysis in Arabidopsis and Antirrhinum have described recessive mutations that cause homeotic conversions of floral organs (Bowman et al 1989; Carpenter and Coen 1990; Coen and Meyerowitz 1991). They either alter the identity of the meristem or affect the identity of floral organs. Molecular genetic analysis of many of these loci suggest a conserved theme that operates for determination of the floral meristem and for the specification of the organ primordia (Coen and Meyerowitz 1991; Ma 1994; Weigel and Meyerowitz 1994). Many of these mutant phenotypes have been observed and utilized by breeders 

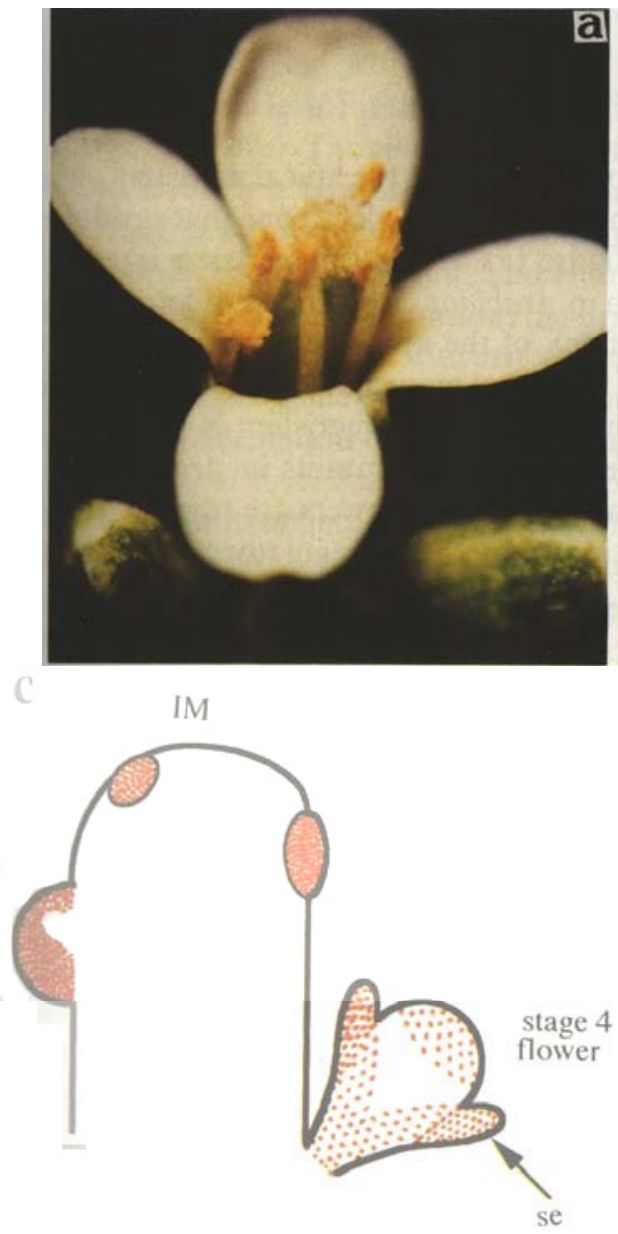

Early RNA expression of $L F Y$

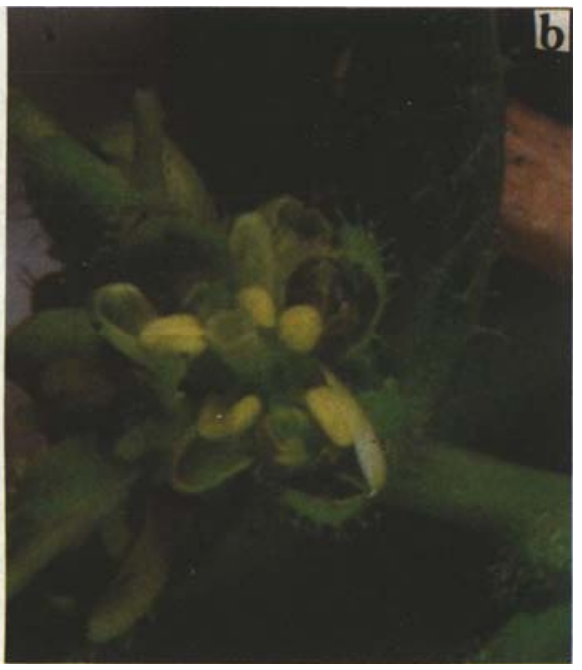

IM

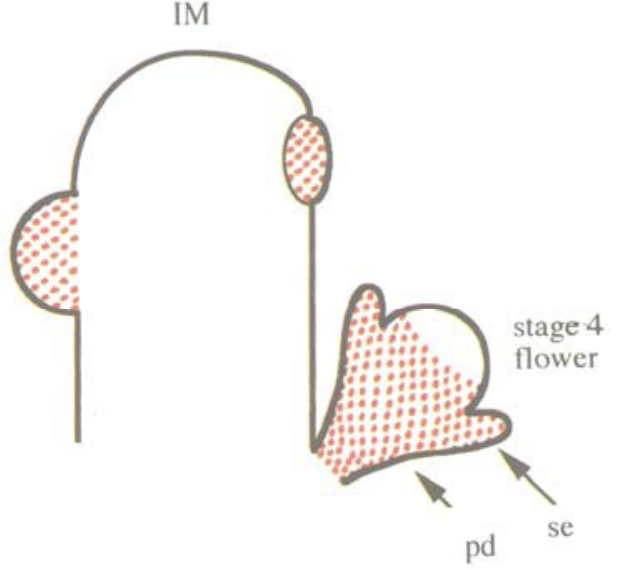

Early RNA expression of $A P I$

Figure 2. (a) A wild type Arabidopsis flower. (b) An apl Arabidopsis flower. Here a single pedicel that should bear an individual flower is now transformed to a branched structure bearing several flowers. In addition in these flowers the sepals are converted to bract like structures and the petals are often aborted. When present the petals have sepaloid characteristics. (c) The RNA expression patterns of the meristem identity genes $L E Y$ and API. A schematic representation of the inflorescence apical meristem is shown on the flanks of which are represented flowers in very early stages of development. $L F Y$ RNA is detectable in a group of cells that are not yet defined morphologically as a flower meristem (Weigel et al 1992). API expression begins slightly later and is observed in the first morphologically detectable protuberance that appears on the flank of the apical meristem (Mandel et al 1992b). (IM, inflorescence meristem; se, sepals).

and horticulturists in many other plants. The similarity in the homeotic phenotypes suggests a high degree of conservation of the mechanisms that specify fate in floral development. 


\section{Specification of floral meristem identity}

\subsection{Genetic analysis of determinants of floral meristem}

In Arabidopsis and in Antirrhinum, upon floral induction, the apical meristem changes from one that produces leaf or branch primordia on its flanks to one that produces an indeterminate number of floral primordia (figure la). This apical meristem is termed an inflorescence meristem. The floral meristem in Arabidopsis begins its differentiation as a group of cells that are set aside on the flank of the apical inflorescence meristem, which morphologically look like the cells of the apical meristem. However, they differ in their developmental programme in that the inflorescence meristem is indeterminate whereas the floral meristem is determinate. Analysis of mutants in Arabidopsis that either fail to produce floral meristems or mutants where flowers are transformed into inflorescence shoots lead to the identification of three key regulatory gene products with partially overlapping functions: $L E A F Y$ ( $L F Y), A P E T A L A 1$ (API), and CAULIFLOWER (CAL). Mutations in $L F Y$ or $A P I$ result in the partial conversion of individual floral meristem into an inflorescence meristem. These mutants therefore repeat an earlier developmental program, and are in some respects similar to the heterochrony mutants of maize (Poethig 1990). Several lines of evidence indicate that $L F Y$ has a more predominant function among these genes in specifying floral meristem identity. The improper specification of floral meristem identity is observed even in weak and intermediate alleles of lfy where the early flowers that are formed have more abnormal characteristics. These flowers have fewer petaloid and stamenoid organs and often have secondary flowers developing internal to the primary flower (Weigel et al 1992). Thus, the petals and stamens are more sensitive to reduction of $L F Y$ activity. In strong alleles of lfy the flowers are more severely affected and they exhibit several characteristics of inflorescences, i.e., they are subtended by bracts, the floral organs are most often leafy sepals, carpels do develop but abnormally, petals and stamens are absent and most floral organs arise in a spiral configuration rather than the whorled configuration of organs in flowers (Weigel et al 1992). However, even in the most severe of the lfy alleles there is a only a partial conversion of flowers to inflorescence. The sequence homologue of $L F Y$ in Antirrhinum is FLORICULA (FLO) and mutations at this locus cause a more severe phenotype when compared to Ify mutants (Coen et al 1990). In most flo plants floral meristems fail to form and are replaced by shoots. The Arabidopsis API gene product is also required for specification of floral meristem identity as is its sequence homologue in Antirrhinum: SQUAMOSA (SQUA) (Irish and Sussex 1990; Huisjer et al 1992; Bowman et al 1993). However, in weak alleles of apl floral meristem identity is not altered perceptibly and individual flowers do not bear any characteristics of shoots. In the intermediate and strong alleles of apl individual flowers are transformed into branched structures that bear flowers at the axil of their first whorl organs (see figure $2 \mathrm{a}$ for a wild type flower and figure $2 \mathrm{~b}$ for an $a p 1$ flower). That the partially redundant $L F Y$ and $A P l$ gene products act synergistically was revealed upon examination of floral meristems in plants that are doubly mutant for lfy and ap (Bowman et al 1993; Schultz and Haughn 1993; Weigel and Meyerowitz 1993). In these plants the flowers show a more complete transformation to inflorescences than that seen in either strong alleles of lfy or apl The third locus $C A L$, originally identified as an enhancer of aplalleles, plays a minor role in specifying floral meristem identity since the cal mutation alone does not have any effect on floral meristem identity 
(Bowman et al 1993). From the analysis of single, double, and triple mutant plants for these loci it has been proposed that $L F Y$, and $A P 1$ activities are required above a certain threshold level for the primordia arising on the flanks of the apical meristem to be specified as floral. The early activities of these two genes are proposed to reach the threshold level by a reinforcing action that they have on each other's activity. The APETALA2 gene product also functions in reinforcing the activity levels of $L F Y$ and AP1 (Bowman et al 1993; Schultz and Haughn 1993). When the activity of either LFY or $A P I$ is reduced (due to mutation) the primordia are intermediate between the floral and inflorescence meristem. Further reduction in the level by a second mutation in either of these two gene products or a mutation in $C A L$ or $A P 2$ results in a more complete transformation of the floral primordia to inflorescence primordia.

While $L F Y, A P I, A P 2$, and $C A L$, promote the formation of floral meristems on the flanks of the inflorescence meristem, the TERMINAL FLOWER (TFL) gene product of Arabidopsis acts to repress floral meristem formation. Mutations in TFL result in earlier flowering because of a shorter vegetative phase of development, and in addition in $t f l$ mutants the apical meristem is transformed into a floral meristem (Shannon and Meeks-Wagner 1991; Alvarez et al 1992). Therefore TFL appears to control the time in the plant life cycle when flower formation should take place and it is likely to repress the activity of floral meristem promoting genes in the apical meristem (Weigel et al 1992; Gustafson-Brown et al 1994). It appears that in Arabidopsis the reproductive pathway promoting the formation of the inflorescence meristem and then the formation of flowers is itself a default pathway because, mutations in EMBRYONIC FLOWER $(E M F)$ lead to production of a single flower upon seed germination (Sung et al 1992). Therefore like $T F L$ this gene product most likely acts to repress the activity of genes like $L F Y$, and $A P 1$ that promote flower formation.

\subsection{Molecular analysis of floral meristem identity}

The cloning and sequence analysis of $L F Y$ and $A P 1$ and of their homologues from Antirrhinum, FLO and SQUA, suggests that these genes function as transcription regulators that specify the identity of the floral meristem. The genetic prediction that $L F Y$ and $A P I$ gene products are required early in the floral development programme for the establishment of the floral meristem identity is supported by the analysis of their in situ expression pattern. The RNA expression pattern of $L F Y$ in wild type flowers shows it to be expressed on the flanks of the apical inflorescence meristem before the development of any morphological sign of the floral meristem. In addition consistent with predictions of the genetic analysis the $L F Y$ RNA is not detected in the apical inflorescence meristem (Weigel et al 1992 and see figure 2c). $L F Y$ RNA continues to be expressed strongly in early floral primordia, but in later stage flowers the levels of $L F Y$ RNA observed are low and there is no detectable signal in the sepals. The FLO RNA is expressed first in the developing bracts; in the axils of which floral primordia develop at a slightly later stage. The expression in bracts is followed by sequential expression, first in the early floral primordia, then in the sepal primordia, and later in the carpel primordia (Coen et al 1990). This cascade of FLO expression pattern is different from what is observed for $L F Y$, therefore while $F L O$ and $L F Y$ bear extensive sequence homology they are likely to control development in different ways. The suggestion of divergence of function among $L F Y$ sequence homologous present in different species is 
substantiated by the studies on the tobacco NFL1 gene. Surprisingly NFL1 RNA expression is seen the indeterminate vegetative meristems and arrested vegetative axillary meristems, in addition to the expected expression in floral meristems (Kelly et al 1995). Regardless of these differences a recent report suggests that $L F Y$ is functionally conserved. The ectopic activity of single genes either $L F Y$ or $A P 1$ was found to be sufficient to promote a floral fate to primordia that in wild type plants have a different fate (Mandel and Yanofsky 1995; Weigel and Nilssen 1995). Transgenic Arabidopsis or aspen plants that constitutively express $L F Y$ develop flowers precociously and flowers appear in the place of lateral shoots. These experiments show that $L F Y$ alone behaves as a developmental switch and they also demonstrate the high degree of functional conservation among diverse species (Weigel and Nilssen 1995). Although the predicted $L F Y$ and FLO class of gene products do not show any similarity to any other known transcription factors, they contain proline rich and acidic domains characteristic of transcription factors. That they are likely to act as transcriptional regulators is supported by the finding that the $L F Y$ product is nuclear localized (D Weigel and E M Meyerowitz, personal communication).

The two other genes in Arabidopsis that are required for floral meristem identity: $A P 1$ and $C A L$ are also cloned and this was done on the basis of the presence of a highly conserved DNA binding motif called the MADS domain (see following section on floral organ identity for MADS domain). The $A P 1$ RNA is detected in very early floral primordia, slightly later than the onset of $L F Y$ expression (Mandel et al 1992b; and see figure 2c). This early and uniform expression of $A P I$ throughout the floral meristem is later restricted to the sepal and the petal primordia at about the time that floral organ identity gene: AGAMOUS is expressed (Gustafson-Brown et al 1994). This expression continues in the sepal and petal of the near mature flower. The biphasic expression pattern of $A P 1$ is consistent with the genetic analysis of apl alleles that suggested two functions for $A P 1$ one in determining floral meristem identity and another as an organ identity gene that specifies sepal and petal development. The $C A L$ gene is also expressed early in floral primordia at about the time that AP1 RNA is detected, but the expression of $C A L$ in the mature flower i.e., in the sepal and the petal is very low (Kempin et al 1995). Therefore, this suggests that while $C A L$ can substitute for $A P 1$ in determining meristem identity, it may not substitute for $A P 1$ in organ identity determination.

The fourth factor $A P 2$ that acts to reinforce the activity of $L F Y$ and $A P 1$ in determining meristem identity has also been cloned (Jofuku et al 1994). However, the expression pattern of $A P 2$ RNA is not restricted to floral meristems and therefore is different from the other genes described above. RNA expression is observed in the leaf primordia, apical meristem, and in floral primordia. The sequence analysis of $A P 2$ shows it to contain a unique 68 amino acid repeated motif that has been called the AP2 motif. This domain is closely related to a DNA binding domain found in ethylene response element binding proteins (Weigel 1995). Apart from functioning in reinforcing meristem identity $A P 2$ like $A P 1$ also has a later function in specification of sepal and petal primordia in the developing floral meristem.

Genes tha $\mathrm{t}$ define the identity of the meristem most likely function as a bridge between floral induction genes and the downstream genes that specify fate of the floral organ primordia. However, their expression must be under the control of other genes, for example, those that directlyrespond to the environment and other cues that induce the conversion of the apical meristem to an inflorescence meristem. While not much is 
known about these genetic factors that induce formation of an inflorescence meristem, genes such as $T F L$ are known to repress $L F Y$ and $A P 1$ from being expressed in the apical inflorescence meristem (Weigel et al 1992; Gustafson-Brown et al 1994).

\section{Floral organ identity genes}

\subsection{The ABC model for floral organ specification}

Once the identify of the meristem is specified, the next step in floral development is the specification of the type, number, and position of organs that are typical for a flower of the particular species. In the case of Arabidopsis this involves the correct specification of four sepals, four petals, six stamens and a central carpel (figures $1 b$ and 2a). Several Arabidopsis and Antirrhinum genes have been studied mutations in which cause homeotic transformation of floral organs (Bowman et al 1989; Carpenter and Coen 1990). In Arabidopsis the genes include $A P 2, A P 1, A P 3, P I$, and $A G$. Each of these genes controls the identity of developing organ primordia that are specified on the floral meristem. $A P 2$ and $A P 1$ activities are required for specification of organ fate in the first and second whorl. Mutations in these loci lead to mis-specification of these specific organ primordia; in apl mutants the sepals are replaced by bract like structures and the petals are often aborted or when present are sepaloid (see figure 2b), in ap2 the sepals are replaced by carpelloid structures and petals by stamens. Mutations in AP3 or PI genes lead to the mis-specification of the second and third whorl organs, with petals being replaced by sepals, and stamens by carpels. Mutations in $A G$ cause misspecification of third and fourth whorl organs, resulting in transformation of stamens into petals and carpels into sepaloid structures. In addition ag flowers loose the determinate characteristic of flowers and reiteration of flower development occurs within the fourth whorl of every flower. These flowers that develop internal to the fourth whorl of the primary flower also bear the same mutant phenotypes. Thus it is apparent that mutations that affect floral organ identity alter the fate of organs that develop in adjacent two whorls of the flower.

Based on the detailed genetic analysis in Arabidopsis of various double and triple mutant combinations a model for the control of the organ identity has been proposed. This model proposes that by the individual and combined expression pattern of three classes of regulatory genes A, B and C a pattern of four different whorls can be specified (reviewed in Coen and Meyerowitz 1991; Ma 1994; Weigel and Meyerowitz 1994). This model proposes that expression of the regulatory gene A alone is sufficient to specify sepal identity, that of $\mathrm{A}$ and $\mathrm{B}$ specifies petal development, that of $\mathrm{B}$ and $\mathrm{C}$ specifies stamen development and of $\mathrm{C}$ alone specifies carpel development. In addition the genetic analysis proposes that the $\mathrm{A}$ and $\mathrm{C}$ activities act antagonistically to restrict each other to specific domains (see figure 3). Many aspects of this model have been borne out by molecular genetic analysis in both plant species. Molecular analysis of several of the Arabidopsis and Antirrhinum genes that are organ specification genes (class A, B, or C) shows them to be members of a class of transcription factors with the conserved MADS-DNA binding domain. The conserved stretch of about 56 amino acids first found in the AGAMOUS and DEFICIENS genes of Arabidopsis and Antirrhinum respectively, bore remarkable similarity to transcription factor SRF of mammalian cells and MCM of yeast. This domain was therefore called the MADS domain to 


\section{WILD TYPE \\ $A B C$}

apetala 2

$a B C$

agamous

$A B C$

apetala3

$A b C$
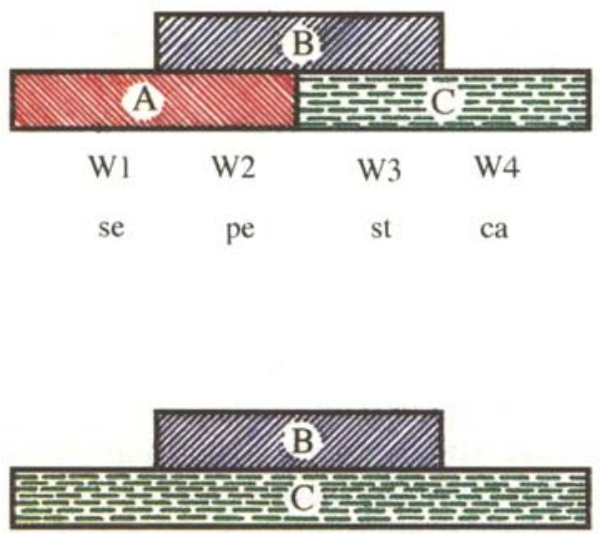

W1

$\begin{array}{rcc}\text { W2 } & \text { W3 } & \text { W4 } \\ \text { st } & \text { st } & \text { ca }\end{array}$

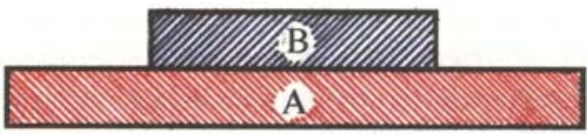

$\begin{array}{rrrr}\text { W1 } & \text { W2 } & \text { W3 } & \text { W4 } \\ \text { se } & \text { pe } & \text { pe } & \text { se }\end{array}$

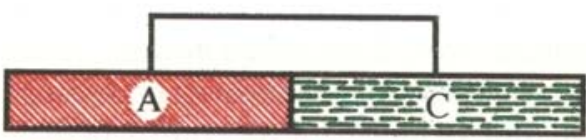

$\begin{array}{lccc}\text { W1 } & \text { W2 } & \text { W3 } & \text { W4 } \\ \text { se } & \text { se } & \text { ca } & \text { ca }\end{array}$

Figure 3. The ABC model for specification of floral organ identity (based on Coen and Meyerowitz 1991; Weigel and Meyerowitz 1994). The domain of action of the class A, B, and $\mathrm{C}$ genes are given within boxed areas in red, blue and green respectively. The altered domains of function and the homeotic transformations of the floral organs observed in flowers with single mutations in each of the class A, B, or C genes are also shown. Wild type genes are denoted by upper case italicized letters and the mutant genes with lower case italicized letters. (W1, whorl 1; W2, whorl 2; W3, whorl 3; W4, whorl 4; se, sepals; pe, petals; st, stamens; ca, carpels).

represent the first four members of this class of transcription factors. The proposed domains of action of these organ identity genes correlates well with the expression patterns of their RNAs. For instance the C class gene, $A G$ of Arabidopsis, is expressed in the region of the floral meristem where the stamens and the carpels are to develop and 
its earliest expression is seen just after the emergence of the sepal primordia but before the morphological development of stamens and carpels (Yanofsky et al 1990; and see figure 4). Similarly, the class B gene $A P 3$ is expressed in the region of the floral meristem where the petal and stamen primordia are to develop; and mutations in this gene cause homeotic transformations in these whorls only (Jack et al 1992; and see figures 3 and 4). The proposal that the $\mathrm{A}$ and $\mathrm{C}$ function genes antagonistically regulate each others expression is supported by the observation that the expression of the $\mathrm{C}$ function gene expands to whorls one and two in plants with mutations in a class A gene: $A P 2$ (Drews et al 1991; and see figure 4). AP1, another class A gene serves only a minor role in repressing $A G$ expression in the first and the second whorl. The negative regulation of $A P 1$ expression in the third and fourth whorl of the flower by the $\mathrm{C}$ function gene is also at the level of transcriptional regulation since in ag mutant flowers $A P 1$ expression expands to the inner whorls of the flower (Gustafson-Brown et al 1994; and see figure 4). The expression pattern studies of $\mathrm{B}$ function genes shows that their early expression pattern is independent of $\mathrm{A}$ or $\mathrm{C}$ function genes. While these initial patterns of expression of the two B function genes $A P 3$ and $P I$ are established independent of each other, high levels of $P I$ expression require $A P 3$ activity implying a role for $A P 3$ in the maintenance of $P I$ activity (Jack et al 1992; Goto and Meyerowitz 1994). Similarly $P I$ also functions as a maintenance factor for $A P 3$ expression in the third whorl and these two B function genes operate in an autoregulatory circuit. That these proteins interact in solution has also been demonstrated (Goto and Meyerowitz 1994). The class $\mathrm{A}, \mathrm{B}$, and $\mathrm{C}$ genes are themselves sufficient for floral organ identity as demonstrated by tudies in Arabidopsis where ectopic expression of one or two genes can result in homeotic transformations. Ectopic expression of $A G$, through a constitutive promoter

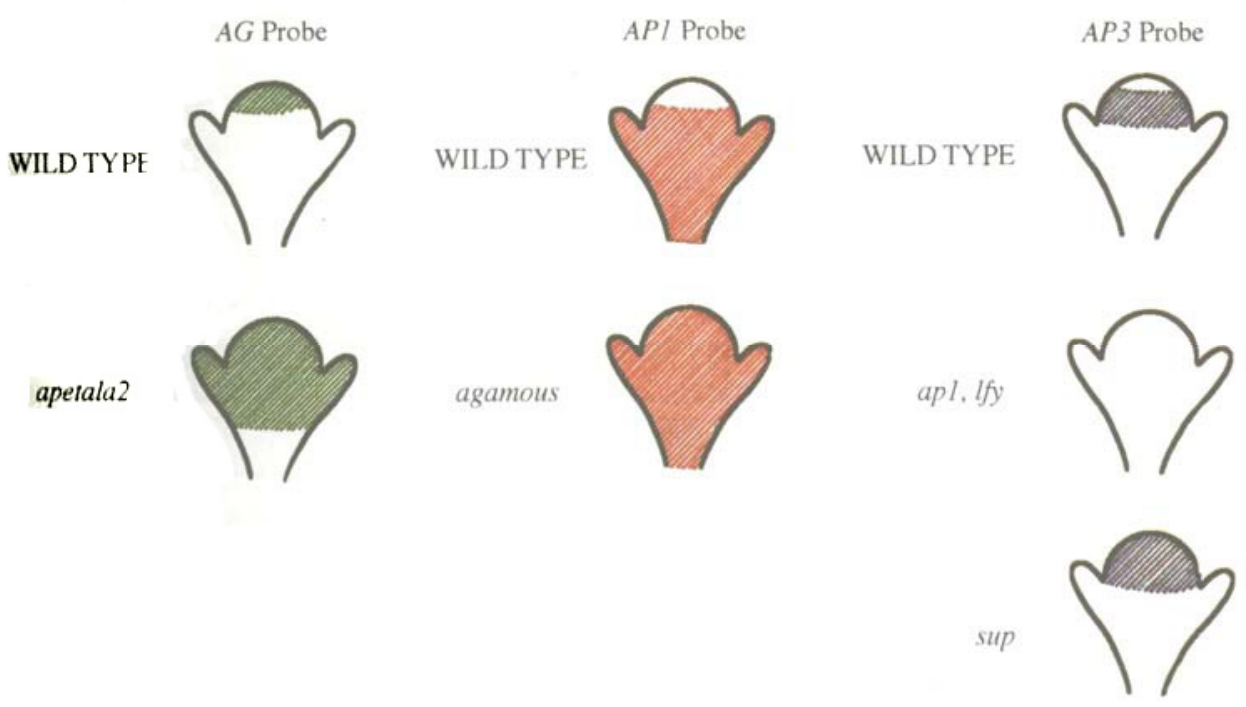

Figure 4. A schematic representation of the RNA expression pattern for the three homeotic floral organ identity genes in wild type and mutant flowers. The flowers shown here are all in stage four of development (Smyth et al 1990) where sepal primordia are defined morphologically but none of the other organ primordia are differentiated yet. The expression pattern for the three different genes are depicted in three columns and the rows give the genotype of the flowers. 
in transgenic Arabidopsis plants results in the conversion of first whorl organs to carpelloid sepals and conversion of the second whorl organs to stamenoid petals (Mizukami and Ma 1992; and see figure 5). This experiment showed that $A G$ alone can

\section{WILD TYPE $A B C$}

apetala 2

$a B C$

WILD TYPE

35 S- AGAMOUS
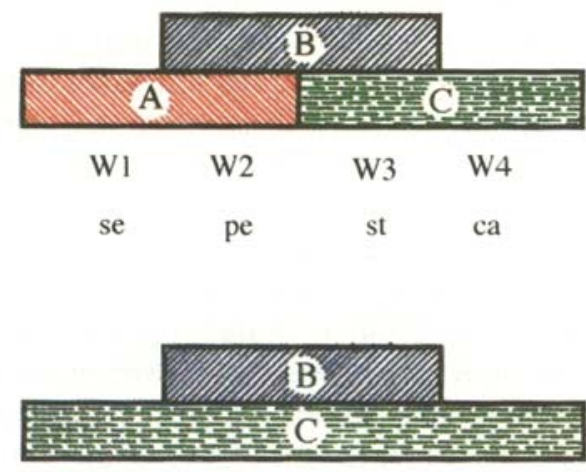

W1

ca

$\begin{array}{cc}\text { W3 } & \text { W4 } \\ \text { st } & \text { ca }\end{array}$

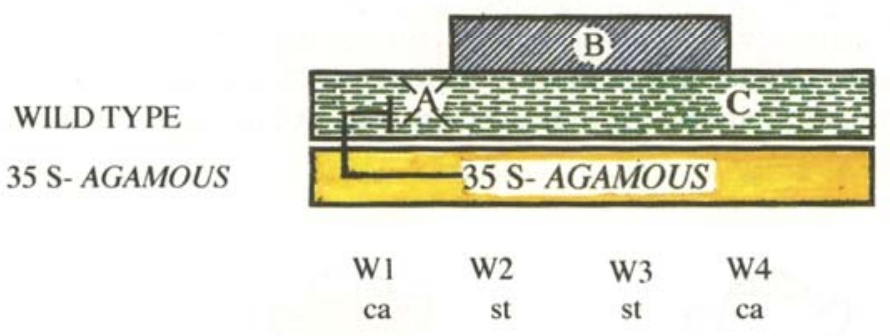

WILD TYPE

35 S- APETALA3

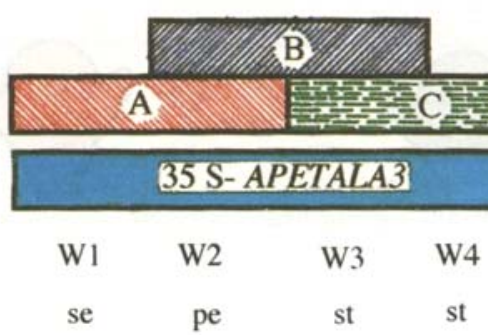

Figure 5. The effects of ectopic expression of individual floral homeotic genes. The first row depicts the domain of expression of the $\mathrm{ABC}$ class of genes in wild type flowers. The second row gives the expression domains of $\mathrm{B}$ and $\mathrm{C}$ genes in a plant mutant for $a$. The third row gives the effects of expressing a class $\mathrm{C}$ gene: $A G$ constitutively in all four whorls of the flower. In this case a phenocopy of $a$ mutant is produced by repression of class A genes in whorl 1 and 2 by the ectopically expressed $A G$. The fourth row shows the effects of ectopic expression of a class B gene of Arabidopsis: AP3. A homeotic conversion of the fourth whorl into stamens is observed. The abbreviations used for the whorls and floral organs are the same as that used in figure 3 . 
repress A function activity and is alone sufficient to direct carpel development. A similar conclusion was arrived at for Antirrhinum where a dominant gain of function mutation in PLENA (PLE), homologue of $A G$ in Antirrhinum, results in phenocopy of a loss of A function (Bradley et al 1993). Ectopic expression of the Arabidopsis $\mathrm{B}$ function gene $A P 3$ demonstrates that the constitutive expression of $A P 3$ in the fourth whorl stabilizes a transient expression of $P I$ in the fourth whorl. Once a stabilized continued expression of $A P 3$ and $P I$ is obtained a conversion of the fourth whorl carpels into stamens is observed (Jack et al 1994; and see figure 5). Transgenic Arabidopsis plants that constitutively express both $A P 3$ and $P I$ develop only petals and stamens showing that these two genes alone are sufficient to provide petal identity in combination with class $\mathrm{A}$ genes and stamen identity in combination with class $\mathrm{C}$ genes (Krizek and Meyerowitz 1996). The fact that the class A, B, and C organ identity genes act similarly in distantly related plant species was demonstrated by experiments where A $G$ sequence homologue from Brassica (Mandel et al 1992a), petunia (Tsuchimoto et al 1993), and tobacco (Kempin et al 1993) were found to repress A function genes when ectopically expressed in transgenic plants.

\subsection{Spatial and temporal regulation of floral organ identity genes}

The temporal and spatial regulation of the organ identity genes on the developing floral meristem must be itself regulated. This regulation must involve activators of these genes since the class $\mathrm{A}, \mathrm{B}$, and $\mathrm{C}$ genes are turned on only in the floral meristem and often only in a specific domain of the developing meristem. In addition repression of their activity in whorls where they should not be expressed is also necessary. Recent studies show that the meristem identity genes are positive regulators of these floral organ identity genes (Bowman et al 1993; Schultz and Haughn 1993; Weigel and Meyerowitz 1993). Genetic analysis of an allelic series of lfy mutants and double mutants analysis suggested that $L F Y$ is an activator of $A P 3$. This prediction based on genetic data has support from analysis of RNA expression pattern of class B genes: $A P 3$, and $P I$ and of a class $\mathrm{C}$ gene: $A G$ in plants mutant for lfy or lfy, and ap1. These experiments showed that $L F Y$ is the predominant activator of class $\mathrm{B}$ genes because RNA levels for B function genes are drastically reduced in lfy plants and this reduced B activity is not altered in lfy, apl double mutant plants (Weigel and Meyerowitz 1993). Similar experiments showed that $L F Y$ and $A P 1$ together act as activators of class $\mathrm{C}$ gene: $A G$ (Weigel and Meyerowitz 1993). Thus the requirement for activators is different for different organ identity genes. Recent studies in Antirrhinum showed that $F L O$; the counterpart of $L F Y$ in Antirrhinum; acts non-autonomously to induce $D E F$ and PLE expression (Hantke et al 1995). These results show that while LFY and FLO are likely to be transcription factors the downstream events that they affect are likely to be brought about by cell-signalling. This must therefore involve other genes that link the early acting meristem identity genes and the step involving the activation of organ identity genes. One such intermediate step in Antirrhinum is controlled by the gene FIMBRIATA (FIM) (Simon et al 1994). This gene is activated soon after the activation of the meristem identity genes FLO and SQUA but before the expression of the organ identity genes $D E F$ and PLE.

Besides the activators of floral organ identity genes there exist a class of genes, the cadastral genes (those that define boundary lines), most members of which are negative 
regulators that apparently prevent the expression of the floral organ specification genes in inappropriate positions. Some of the organ identity genes themselves have dual functions and operate as cadastral genes too. The negative regulation of $A G$ in whorl one and two by $A P 2$, and the negative regulation of $A P 1$ in whorl three and four by $A G$ are some of such examples (see figure 4). Genes that function purely as cadastral genes without any predominant role in determining organ identity are also known. The SUPERMAN (SUP) gene of Arabidopsis is required to prevent the expression of AP3 in the fourth whorl of the developing flowers (Bowman et al 1992 and see figure 4). The molecular characterization of SUP shows it be a putative transcription factor belonging to a class of proteins with a zinc finger motifs and the expression pattern of SUP suggests a role in maintaining floral whorl boundaries (Sakai et al 1995). Recently another gene LEUNIG (LUG) has been defined that has a cadastral role in restricting $A G$ in whorl one and two of the Arabidopsis flower (Liu and Meyerowitz 1995). These studies, therefore reveal a complex network of interactions among regulatory proteins that together are responsible for determining the fate of cells that constitute the floral meristem.

\section{Conservation of the $A B C$ model for organ specification among different species}

The cloning of several floral organ identity genes has been done from a variety of species on the basis of mutant phenotypes or the presence of the conserved MADS domain first found in Antirrhinum and Arabidopsis genes. The plants where these genes have been cloned from include a diverse range of species including tomato, petunia, tobacco, maize and rice (Angenent et al 1992, 1994; van der Krol et al 1993; Pnueli et al 1991; Kempin et al 1993; Schimdt et al 1993; Chung et al 1994). In most species a predominant fraction of the genes cloned on the basis of the presence of the MADS domain turn out to be genes that are preferentially expressed in inflorescence meristem, or floral meristem, or in a part of the flower. However, some MADS domain containing genes are expressed in vegetative tissues implying a role for proteins containing this domain in a wide range of biological activities (Ma el al 1991). The cloning of organ specification genes from a range of species has allowed a test of the functional conservation of these molecules. The Brassica napus homologue of the Arabidopsis AGAMOUS gene was cloned on the basis of DNA sequence homology and this gene was then ectopically expressed in transgenic tobacco plants, lowers formed on these plants showed homeotic transformation of sepals into carpels and petals into stamens. These homeotic conversions were consistent with the conclusion that the ectopically expressed Brassica $A G$ can suppress the A function genes of tobacco resulting in a phenocopy of a gain of $\mathrm{C}$ function (Mandel et al 1992a and see figure 5). The remarkable conservation of function of $A G$ from Brassica in transgenic Nicotiana reinforces the idea that floral organ identity can be altered though the action of a few regulatory genes, just as meristem identity can be altered by the action of single genes like LFY or API (Weigel and Nilssen 1995; Mandel and Yanofsky 1995).

The studies on the expression pattern of the MADS box containing genes from these varied species shows that the domain of expression is not always only in two adjacent whorls as observed for Arabidopsis and Antirrhinum MADS box genes. For e.g., the tomato TM5 and the petunia FBP2 genes are expressed in three consecutive inner whorls (Angenent et al 1994; Pneuli et al 1994), and the rice Os MADS1 gene is expressed in lemma and palea (modified bracts) and in the ovary (Chung et al 1994; and see figure 6 for data from this laboratory). In fact in some cases the effects of mutations in sequence homologues 

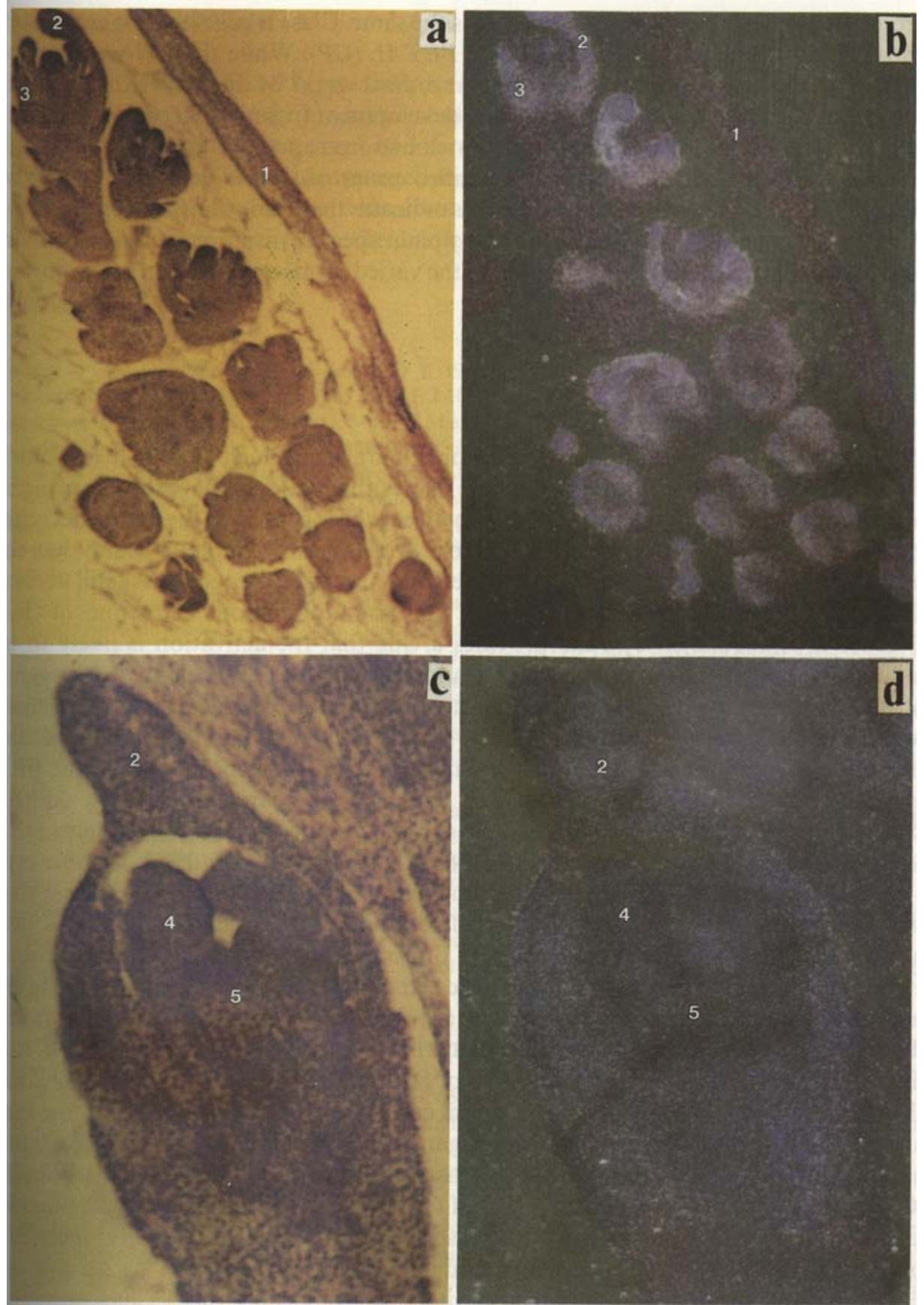

Figure 6. In situ analysis of the RNA expression domain of the OS MADS1 gene of rice. A fragment of the gene that contains the $3^{\prime}$ non-MADS region of the gene was used for the preparation of antisense RNA that was radio-labelled with $\mathrm{S}^{35} \mathrm{UTP}$. This antisense RNA was hybridized to $8 \mu \mathrm{m}$. thick sections of developing rice panicles according to the procedures specified by Drews et al (1991). The slides were developed after one week, (a) and (c) represent bright field photographs, and (b) and (d) show the same frames photographed in dark field. The hybridization signal in the dark field photographs is visible as silver to white grains. 1, leaf sheath; 2, lemma; 3, palea; 4, stamen; 5, carpel. 
present in two different species is not always the same. Class $\mathrm{B}$ gene homologue of $A P 3$ and DEF in petunia is the gene GREEN PETAL (GP). While the RNA expression pattern of $G P$ is restricted to the second and third whorl of the flower the effects of mutations in this gene are seen only petal development (van der Krol et al 1993). In addition some new MADS domain genes cloned from petunia and tomato do not correspond to any of the currently identified genes of Arabidopsis or Antirrhinum (Pnueli et al 1991; Angenent et al 1992). This indicates that while the basic aspects of the ABC model are likely to hold true for many plant species, variations in this theme are likely to be informative on the evolution of the varied forms and function of the flowers that we observe.

\section{Challenges ahead}

While a number of aspects of floral development are being elucidated by these studies many challenges still remain. Of these some interesting ones are what are the activators of the meristem identity genes and the link between these genes and the genes that sense growth conditions of the plant. While some evidence is available to show that the meristem identity genes are activators of the floral organ identity genes it is still unclear if this is a direct or indirect mechanism. The non-autonomous activation of class B genes in Antirrhinium by FLO provides a clue that the activation is likely to be indirect (Hantke et al 1995). The downstream targets of the floral organ identity genes of all three classes are yet to be defined. Some aspects of the biochemical nature of these organ identity genes will soon be available. Recent in vitro studies have shown that the $A G$ protein does bind DNA and its binding site is found to be similar to the SRE elements bound by SRF, a mammalian protein that bears this binding domain (Shiraishi et al 1993). In vitro studies have shown that the Antirrhinum proteins DEF and GLO bind DNA only as heterodimers (Scharwz-Sommer et al 1992; Trobner et al 1992). The plant MADS domain containing genes often share a second domain that bears similarity to the coiled coil domain of keratin, and this domain called the $\mathrm{K}$ box has been proposed to function in protein dimerization (Ma et al 1991; Pneuli et al 1991). This proposed function is yet to be tested. Many other questions that are being addressed currently in several laboratories are how are the number of organs that will develop in a flower controlled. Some clues are likely to emerge from the analysis of loci like perianthia of Arabidopsis where the organ number in each whorl is increased (M Running and E M Meyerowitz, personal communication). Another set of loci that are providing clues to determination of organ number are the clavatal, clavata2, and clavata3 loci in Arabidopsis where an increased number of organs is seen in all whorls (Clark et al 1993,1995). Genetic analysis of CLV1 shows the increased organ number arises from a primary phenotype of increased number of cells in the apical meristem both in the vegetative and in the reproductive stage. In addition to its role on determining meristem size $C L V 1$ interacts with meristem identity genes. Clues regarding the development of asymmetry in the case of zygomorphic flowers are like to come from the analysis of mutants like cycloidia of Antirrhinum where the normally zygomorphic flower is converted to one that is radially symmetrical (Carpenter and Coen 1990; Coen and Meyerowitz 1991). An understanding of the underlying mechanisms that determine number and symmetry of organs in flower will even throw light on the development of leaves where questions on pattern, and symmetry are yet to be addressed. 


\section{Acknowledgements}

The cloning of the Os MADS1 gene was done by M B Suresh Kumar and I acknowledge his help in the experiments on the study of its RNA expression pattern. These expression pattern studies are reported here in figure 6 . The work in my laboratory on flower development in rice is supported by a grant from the Rockefeller Foundation, USA; and our work on the Arabidopsis APETALA1 gene was supported by a grant from Department of Science and Technology, New Delhi.

\section{References}

Alvarez J, Guli C L, Yu X-H and Smyth D R 1992 Terminal flower: A gene affecting inflorescence development in Arabidopsis thaliana; Plant J. 2 103-116

Angenenet G C, Busscher M, Franken J, Mol J N M and Van Tunen A J 1992 Differential expression of two MADS box genes in wild type and mutant petunia flowers; Plant Cell 4 983-993

Angenenet G C, Franken J, Busscher M, Weiss D and Van Tunen A J 1994 Co-suppression of the petunia homeotic gene $f b p 2$ affects the identity of the generative meristem; Plant J. 5 33-44

Bateson W 1894 Materials for the study of variation (Cambridge: Cambridge University Press)

Bowman J L, Smyth D R and Meyerowitz E M 1989 Genes directing flower development in Arabidopsis; Plant Cell $137-52$

Bowman J L, Sakai H, Jack T, Weigel D, Mayer U and Meyerowitz E M 1992 SUPERMAN, a regulator of floral homeotic genes in Arabidopsis; Development 114 599-615

Bowman J L, Alvarez J, Weigel D, Meyerowitz E M and Smyth D R 1993 Control of flower development in Arabidopsis thaliana by APETALA1 and interacting genes; Development 119 721-743

Bradley D, Carpenter R, Sommer H, Hartley N and Coen E S 1993 Complementary floral phenotypes result from opposite orientations of a transposon at the plena locus of Antirrhinum, Cell 72 85-95

Carpenter R and Coen E S 1990 Floral homeotic mutations produced by transposon-mutagenesis in Antirrhinum majus; Genes Dev. 4 1483-1493

Chung Y Y, Kim S-R, Finkel D, Yanofsky M F and An G 1994 Early flowering and reduced apical dominance result from ectopic expression of a rice MADS box gene; Plant Mol. Biol. 26 657-665

Clark S E, Running M P and Meyerowtiz E M 1993 CLAVAT Al, a regulator of meristem and floral development in Arabidopis; Development 119 397-418

Clark S E, Running M P and Meyerowitz E M 1995 CLAV AT A3 is a specific regulator of shoot and floral meristem development affecting the same process as CLAV AT Al; Development 121 2057-2067

Coen E S and Meyerowitz E M 1991 The war of the whorls: Genetic interactions controlling flower development; Nature (London) 353 31-37

Coen E S, Romero J M, Doyle S, Elliot R, Murphy G and Carpenter R 1990 floricula: A homeotic gene required for flower development in Antirrhinum majus; Cell 63 1311-1322

Drews G N, Bowman J L and Meyerowitz E M 1991 Negative regulation of the Arabidopsis homeotic gene AGAMOUS by the APETALA2 product; Cell 65 991-1002

Goto K and Meyerowitz E M 1994 Function and regulation of the Arabidopsis floral homeotic gene PISTILLATA; Genes Dev. 8 1548-1560

Gustafson-Brown C, Savidge B and Yanofsky M F 1994 Regulation of the Arabidopsis floral homeotic gene APETALA1; Cell 76 131-143

Hantke S S, Carpenter R and Coen E S 1995 Expression of floricula in single cell layers of periclinal chimeras activates downstream homeotic gene in all layers of floral meristem; Development 121 27-35

Huijser P, Klein J, Lonning W-E, Meijer H, Saedler H and Sommer H 1992 Bracteomania, an inflorescence anomaly is caused by the loss of function of the MADS box gene SQU AMOSA in Antirrhinum majus; EMBO J. 11 1239-1249

Irish V F and Sussex I M 1990 Function of the APETALA1 gene during Arabidopsis floral development; Plant Cell 2 741-753

Jack T, Brockman L L and Meyerowitz E M 1992 The homeotic gene APETALA3 of Arabidopsis thaliana encodes a MADS box gene and is expressed in petals and stamens; Cell 68 683-697

Jack T, Fox G L and Meyerowitz E M 1994 Arabidopsis homeotic gene APETALA3 ectopic expression: transcriptional and post-transcriptional regulation determine floral organ identity; Cell 76 703-716 
Jofuku K D, van den Boer B G W, van Montagu M and Okamuro J 1994 Control of Arabidopsis flower and seed development by the homeotic gene APETALA2; Plant Cell 6 1211-1225

Kelly A J, Bonnlander MB and Meeks-Wagner D 1995 NFL, the tobacco homolog of FLORICULA and $L E A F Y$, is transcriptionally expressed in both vegetative and floral meristems; Plant Cell 7 225-234

Kempin S A, Mandel M A and Yanofsky M F 1993 Conversion of perianth into reproductive organs by ectopic expression of the tobacco floral homeotic gene NAG1; Plant Physiol. 103 1041-1046

Kempin S A, Savidge B and Yanofsky M F 1995 Molecular basis of the cauliflower phenotype in Arabidopsis; Science $267522-525$

Krizek B A and Meyerowitz E M 1996 The Arabidopsis homeotic genes APETALA3 and PISTILLATA are sufficient to provide the B class organ identity function; Development 122 11-22

Liu Z and Meyerowitz E M 1995 LEUNIG regulates AGAMO US expression in Arabidopsis flowers; Development 121 975-991

Ma H 1994 The unfolding drama of flower development: recent results from genetic and molecular analysis; Genes Dev. $8745-756$

Ma H, Yanofsky M F and Meyerowitz E M 1991 AGL1-AGL6, an Arabidopsis gene family with similarity to floral homeotic and transcription factor genes; Genes Dev. 5 485-495

Mandel M A, Bowman J L, Kempin S A, Ma H, Meyerowitz E M and Yanofsky M F 1992a Manipulation of flower structure in transgenic tobacco; Cell 71 133-143

Mandel M A, Gustafson-Brown C, Savidge B and Yanofsky M F 1992b Molecular characterization of the Arabidopsis floral homeotic gene APETALA1; Nature (London) 360 273-277

Mandel M A and Yanofsky M F 1995 A gene triggering flower formation in Arabidopsis: Nature (London) 377 522-524

Mizukami Y and Ma H 1992 Ectopic expression of the floral homeotic gene AGAMOUS in transgenic Arabidopsis plants alter floral identity; Cell 71 119-131

Poethig R W 1990 Heterochronic mutations affecting shoot development in maize; Genetics 119 959-973

Pneuli L, Abu-Abeid M, Zamir D, Nacken W, Schwarz-Sommer Z and Lifschitz E 1991 The MADS box gene family in tomato: temporal expression during floral development, conserved secondary structure and homology with homeotic genes from Antirrhinum and Arabidopsis; Plant J. 1 253-266

Pneuli L, Hareven D, Broday L, Hurwitz C and Lifshitz E 1994 The TM5 MADS box gene mediates organ differentiation in three inner whorls of tomato flowers; Plant Cell 6 175-186

Sakai H, Medrano L and Meyerowitz E M 1995 Role of SUPERMAN in maintaining Arabidopsis floral whorl boundaries; Nature (London) 378 199-203

Schmidt R J, Veit M A, Mandel M A, Mena M, Hake S and Yanofsky M F 1993 Identification and molecular characterization of ZAG1, the maize homolog of the Arabidopsis floral homeotic gene, AGAMOUS; Plant Cell 5 729-737

Schultz E A and Haughn G W 1993 Genetic analysis of the floral initiation process (FLIP) in Arabidopsis; Development 119 745-765

Schwarz-Sommer Z, Hue I, Huijser P, Flor P J, Hansen R, Tetens F, Lonnig W-E, Saedler H and Sommer H 1992 Characterization of the Antirrhinum floral homeotic MADS-box gene deficiens: evidence for DNA binding and autoregulation of its persistent expression throughout floral development; EMBO J. 11 251-263

Shannon S and Meeks-Wagner D R1991A mutation in the Arabidopsis TFL1 gene affects inflorescence meristem development; Plant Cell 3 977-892

Shirashi H, Okada K and Shimura Y1993 Nucleotide sequences recognised by the AGAMOUS MADS domain of Arabidopsis thaliana in vitro; Plant J. 4 385-398

Simon R, Carpenter R, Doyle S and Coen E 1994 Fimbriata controls flower development by mediating between meristem identity and organ identity genes; Cell 78 99-107

Smyth D R, Bowman J L and Meyerowitz E M 1990 Early flower development in Arabidopsis; Plant Cell $2755-767$

Sung Z R, Belachew A, Shunong B and Bertrand-Garica R 1992 EMF, an Arabidopsis gene required for vegetative shoot development; Science 258 1645-1647

Trobner W, Ramirez L, Motte P, Hue I, Hiujser P, Lonnig W-E, Saedler H, Sommer H and Schwarz-Sommer Z 1992 GLOBOSA: A homeotic gene which interacts with DEFICIENS in the control of Antirrhinum floral organogenesis; EMBO J. 11 4693-4704

Tsuchimoto S, van der Krol A R and Chua N-H 1993 Ectopic expression of pMADS3 in transgenic petunia phenocopies the petunia blind mutant; Plant Cell 5 843-853

van der Krol A R, Brunelle A, Tsuchimoto S and Chua N-H 1993 Functional analysis of petunia floral homeotic MADS box gene pMADSl; Genes Dev. 7 1214-1228 
Weigel D, Alvarez J, Smyth D R, Yanofsky M F and Meyerowitz E M 1992 LEAFY controls floral meristem identity in Arabidopsis; Cell 69 843-859

Weigel D and Meyerowitz E M 1994 The ABCs of floral homeotic genes; Cell 78 203-209

Weigel D and Meyerowitz E M 1993 Activation of floral homeotic genes in Arabidopsis; Science 261 1723-1726

Weigel D 1995 The APETALA2 domain is related to a novel type of DNA binding domain; Plant Cell 7 388-389

Weigel D and Nilssen O 1995 A developmental switch sufficient for flower initiation in diverse plants; Nature (London) 377 495-500

Yanofsky M F, Ma H, Bowman J L, Drews G W, Feldman K A and Meyerowitz E M 1990 The protein encoded by the Arabidopsis homeotic gene agomous resembles transcription factors; Nature (London) 346 5-39 